\title{
Relationship between trough level of tyrosine kinase inhibitor (imatinib and nilotinib) and BCR- $A B L$ ratios in an Indonesian chronic-phase chronic myeloid leukemia $(\mathrm{CML})$ population by Budi Suprapti
}

Submission date: 10-Aug-2020 09:39PM (UTC+0800)

Submission ID: 1368082048

File name: 21910_1.PDF (383.34K)

Word count: 4311

Character count: 22672 
Budi Suprapti*, Mareta Rindang Andarsari, Pharmasinta Putri Hapsari, Junaidi Khotib, Suharjono and Siprianus Ugroseno Yudho Bintoro

Relationship between trough level of tyrosine kinase inhibitor (imatinib and nilotinib) and $B C R-A B L$ ratios in an Indonesian chronic-phase chronic myeloid leukemia (CML) population

http s://doi. org/10.1515/jbcpp-2019-0315

Received October 23, 2019; accepted April 7, 2020; published online $\mathrm{xxx}$

\section{Abstract}

Objectives: Among Chronic Myeloid Leukemia (CML) patients treated with Tyrosine Kinase Inhibitor (TKI-imatinibnilotinib), some showed a suboptimal response. Based on pharmacokinetic studies, TKI trough level $\left(C_{\min }^{\infty}\right)$ is associated with clinical outcomes, reflected by the BCR-ABL ratio. However, the interindividual pharmacokinetic variability of imatinib and nilotinib is found to be moderate-high. This study aims to analyze the relationship between TKI $C_{\min }^{\infty}$ and BCL-ABL ratio in chronic-phase CML patients.

Methods: Cross-sectional study to CML chronic-phase patie 60 treated with imatinib $400 \mathrm{mg}$ daily or nilotinib 400 or $800 \mathrm{mg}$ daily for $\geq 12$ months. The exclusion criteria were therapy discontinuation within 29 days (imatinib) or 8 days (nilotinib) before the sampling day. Blood samples were drawn $1 \mathrm{~h}$ before the next dose. Imatinib-nilotinib $C_{\text {min }}^{\infty}$ and BCR-ABL ratio were measured using HPLC and RT-qPCR. The relationship was analyzed using bivariate correlation Spearman's rho test.

Results: Twenty-three imatinib and 11 nilotinib patients met the inclusion criteria. The mean imatinib and nilotinib $C_{\min }^{\infty}$ were $1,065.46 \pm 765.71$ and $1,445 \pm 1,010.35 \mathrm{ng} / \mathrm{mL}$ respectively. There were large interiodividual variations in both groups $(71.87 \%$ vs. $69.88 \% 8$. Half of the patients in each group were found to reach $C_{\min }^{\infty}$ target $(\geq 1.000 \mathrm{ng} / \mathrm{mL}$,

*Corresponding author: Budi Suprapti, Department of Clinical Pharmacy, Airlangga University, Campus C Jalan Mulyorejo, Surabaya, East Java, 60115, Indonesia, E-mail: budi-s@ff.unair.ac.id Mareta Rindang Andarsari, Pharmasinta Putri Hapsari, Junaidi Khotib and Suharjono: Faculty of Pharmacy, Department of Clinical Pharmacy, Airlangga University, Surabaya, East Java, Indonesia Siprianus Ugroseno Yudho Bintoro: Hematology Oncology Division, Department of Internal Medicine, Dr Soetomo General Hospital, Surabaya, East Java, Indonesia imatinib; $\geq 800 \mathrm{ng} / \mathrm{mL}$ nilotinib), but only $12(35,29 \%)$ of them result in BCR-ABL ratio $\leq 0.1 \%$. $C_{\min }^{\infty}$ imatinib was found to be significantly associated with BCR-ABL ratio. But, not with the nilotinib group.

Conclusions: There were high interindividual variations of imatinib and nilotinib correlated with BCR-ABL ratio, but no correlation in nilotinib.

Keywords: $\mathrm{BCR}-\mathrm{ABL}$ ratio; $C_{\min }^{\infty}$; $\mathrm{CML}$; imatinib; nilotinib.

\section{Introduction}

22

The development of tyrosine kinase inhibitors (TKI) has changed the management of Chronic Myeloid Leukemia (CML) therapy from lethal cancer to controlled chronic jisease $[1,2]$. Imatinib and nilotinib selectively inhibit tyrosine kinase activity by occupying the Adenosine Tryphosphate (ATP) binding domain in ABL so as to prevent substrate phosphorylation. The inhibition of phosphorylation of the substrate will inactivate the nucleus and cytoplasmic signal transduction pathways, including RAS, phosphaidylinositol-3 kinase - alpha serine/threonine kinase (PI3K-Akt) and Janus kinase - signal transducers and activators of transcription (JAK-STAT) which cause a decreased proliferation and increased cell apoptosis [3].

Imatinib mesylate is the first generation of TKI, which can induce therapeutic responses including hematological response (leucocyte), cytogenetic response (presence/ absence of cells containing the Philadelphia chromosome), and molecular response (BCR-ABL ratio) in more than $80 \%$ of CML patients $[4,5]$. Although imatinib is known to produce a high cytogenetic response, some patients do not respond to imatinib therapy or relapse after a primary 55 sponse. Nilotinib is one of the second generation ${ }_{34}$ TKI that is approved by the FDA to be used as therapy in CML patients who are resistant or intolerant to imatinib $[6,7]$.

The BCR-ABL ratio is a parameter of the TKI molecular response, expressed the ratio of $\mathrm{BCR}-\mathrm{ABL}$ transcription 
25 el to $\mathrm{ABL}$ with a target of $\leq 1 \%$ after 12 months of therapy. CML patients treated with imatinib or nilotinib showed that decreasing of BCR-ABL transcript levels occurred most rapidly in 6 months on TKI and reached the plateau at 1215 months after therapy [8]. Data in Dr. Soetomo General Hospital, Surabaya, showed that there was an increase in CML cases from 58 patients in 2006 to 160 patients in 2014 [9] and molecular response attained in $40 \%$ patient 50 nly.

Based on pharmacokinetic studies, there is a relationship between of TKI $C_{\min }^{\infty}$ and therapeutic response [10]. Additionally, there was high variability in TKI $C_{\min }^{\infty}$. The coefficient of interindividual variation in $C_{\min }^{\infty}$ of imativib and nilotinib is $45-50 \%$ [11]. One of the factors that influence the suboptimal response to TKI therapy is the variation of pharmacokinetic factors and/or drug interactions that affect the pharmacokinetics of TKI [12]. This study was conducted to determine the rela 14 ship between the TKI $C_{\min }^{\infty}$ (imatinib and nilotinib) and BCR-ABL ratio in patients with chronic phase CML who had used TKI, either imatinib or nilotinib, for $\geq 12$ months therapy.

\section{Materials and methods}

\section{Study design and population}

This o 30 vational study was conducted on adult patients (age $\geq 18$ years) with a diagnosis 47 hronic phase CML who had been treated with TKI, both imatinib $400 \mathrm{mg} /$ day or nilotinib 400 or $800 \mathrm{mg} /$ day for $\geq 12$ months. The exclusion criteria were the discontinuation of therapy within 29 days (imatinib) or 8 days (nilotinib) before the sampling day. All subjects gave informed consent before the study. The study was approv 12 y Dr. Soetomo General Hospital Ethical Review Committee and conducted in accordance with the criteria set by the declaration of Helsinki.

\section{Study protocol}

About $8 \mathrm{~mL}$ of blood was drawn from each patient within $\pm 1 \mathrm{~h}$ before the next dose. Blood samples were collected in two separate vacutainers for determination of $C_{m i}^{\infty} 24$ TKI $(5 \mathrm{~mL})$ and BCR-ABL ratio $(3 \mathrm{~mL})$. Imatinib and nilotinib levels were measured using HighPerformance Liquid Chromatography (HPLC) method, and the BCR-ABL ratio is measured using RT-qPCR.

\section{Measurements of $C_{\min }^{\infty}$ of imatinib and nilotinib}

Trough levels of imatinib and nilotinib in plasma were measured by the HPLC r 20 od. About $500 \mu \mathrm{L}$ of plasma added, then $500 \mu \mathrm{L}$ acetonitrile a $200 \mu \mathrm{L}$ of the internal standard solution with a concentration of $50 \mu \mathrm{g} / \mathrm{mL}$ in methanol (the internal standard used for imatinib assay was nilotinib, and for nilotinib assay was imatinib), then centrifuged $6,000 \times \mathrm{g}$ for $10 \mathrm{~min}$. The supernatant obtained was evaporated to dryness with $\mathrm{N}_{2}$ gas, then resuspended in a $500 \mu \mathrm{L}$ mobile phase, and then injected into the HPLC column. The instrument used was the DAD-Agilent 1100 series HP/ 3 machine with RP-C18 columns. The mobile pha 3 used consisted of $40 \%$ solvent A ( $72.5 \%$ water, $25 \%$ methanol, and $2.5 \%$ triethylamine), $20 \%$ methanol, and $40 \%$ acetonitrile, which was flowed at a rate of $0.9 \mathrm{~mL} / \mathrm{min}$ at $35^{\circ} \mathrm{C}$ and isocratic conditions. Eluation was observed at wavelengths of $267 \mathrm{~nm}$ [13].

\section{Measurements of BCR-ABL ratios}

Three mL of blood sample collected in EDTA vacutainer was stored at a temperature of $2-8{ }^{\circ} \mathrm{C}$ and proc 31 d within $48 \mathrm{~h}$ of the initial sampling to avoid degradation of RNA. Measurements of the BCR-ABL ratio in whole blood CML patients were carried out by the RT-qPCR method with the GeneXpert tools. The cartridge preparation process must be carried out within $15 \mathrm{~min}$.

\section{Statistical analysis}

The relationship between the imatinib/nilotinib $C_{\min }^{\infty}$ and BCR-ABL ratio was analyzed by the bivariate correlation Spearman rho test.

\section{Results}

Twenty-three imatinib patients and 11 nilotinib patients met the inclusion criteria and signed informed consent. All subjects in the nilotinib group had a history of being treate $d_{46}$ ith imatinib before being treated with nilotinib. Other patient characteristics data are presented in Table 1.

There were 10 (43.48\%) patients who used imatinib could reach the $C_{\min }^{\infty}$ target $(>1,000 \mathrm{ng} / \mathrm{mL}$ ). In the nilotinib group, there were $7(63.64 \%)$ patients could achieve the $C_{\text {min }}^{\infty}$ target $\left(>800 \mathrm{ng} / \mathrm{mL}\right.$ ). The distribution of $C_{\min }^{\infty}$ from the two groups is presented in Figure 1.

Table 2 shows that the average $C_{\min }^{\infty}$ is $1,065.46 \pm$ $765.71 \mathrm{ng} / \mathrm{mL}$ for imatinib and $1445 \pm 1,010.35 \mathrm{ng} / \mathrm{mL}$ for nilotinib. The data showed there were large interindividual variations in both groups ( $2.87 \%$ vs. $69.88 \%$ ).

The distribution of the BCR-ABL ratio values of the two groups is shown in Figure 2.

Ten $(43.48 \%)$ patients who received imatinib achieved BCR-ABL ratio of $\leq 0.1 \%$, while in nilotinib group achieved in $7(63.64 \%)$ patients.

Within imatinib group, there was a correlation between $C_{\min }^{\infty}$ and $\mathrm{BC}_{29}-\mathrm{ABL}$ ratios $(\mathrm{p}=0.043)$ and the mean of $C_{\min }^{\infty}$ in the group of patients who had a $\mathrm{BCR}_{1} \mathrm{BL}$ ratio $\leq 0.1 \%$ tended to be greater than the group of patients who had a BCR-ABL ratio of $>0.1 \%(1,381.95$ vs. $822.01 \mathrm{ng} / \mathrm{mL})$ (Table 3). In addition, the group of patients who had $C_{\mathrm{min}}^{\infty}$ imatinib $\geq 1,000 \mathrm{ng} / \mathrm{mL}$ had a 2.564 times greater chance of 
Table 1: Basic characteristic of chronic phase-CML patients treated with imatinib or nilotinib.

\begin{tabular}{|c|c|c|c|c|c|c|c|}
\hline \multirow{3}{*}{ Patient's characteristic } & & \multicolumn{3}{|c|}{ Imatinib } & \multicolumn{3}{|c|}{ Nilotinib } \\
\hline & & \multicolumn{3}{|c|}{ Total patient $(n=23)$} & \multicolumn{3}{|c|}{ Total patient $(n=11)$} \\
\hline & & $\mathbf{n}$ & $\%$ & $\bar{x} \pm S D$ & $\mathbf{n}$ & $\%$ & $\bar{x} \pm S D$ \\
\hline \multirow[t]{2}{*}{ Sex } & Man & 11 & 47.8 & - & 5 & 45.5 & - \\
\hline & Woman & 12 & 52.2 & - & 6 & 54.5 & - \\
\hline \multirow[t]{6}{*}{ Age (when CML diagnosed) } & $18-20$ y.o & 1 & 4.3 & $46.70 \pm 12.60$ & - & - & $45.45 \pm 13.69$ \\
\hline & $21-30$ y.o & 3 & 13.1 & Median: 45 y.o & 1 & 9.1 & Median: 46 y.o \\
\hline & $31-40$ y.o & 8 & 34.8 & & 4 & 36.4 & \\
\hline & $41-50$ y.o & 6 & 26.1 & & 2 & 18.2 & \\
\hline & $51-60$ y.o & 4 & 17.4 & & 2 & 18.2 & \\
\hline & $61-70$ y.o & 1 & 4.3 & & 2 & 18.2 & \\
\hline \multirow[t]{8}{*}{ Weight } & $31-40 \mathrm{~kg}$ & 2 & 8.7 & $62.30 \pm 14.61 \mathrm{~kg}$ & - & - & $59.45 \pm 7.61 \mathrm{~kg}$ \\
\hline & $41-50 \mathrm{~kg}$ & 1 & 4.3 & & - & - & \\
\hline & $51-60 \mathrm{~kg}$ & 11 & 47.8 & & 7 & 63.6 & \\
\hline & $61-70 \mathrm{~kg}$ & 3 & 13.1 & & 2 & 18.2 & \\
\hline & $71-80 \mathrm{~kg}$ & 3 & 13.1 & & 2 & 18.2 & \\
\hline & $81-90$ kg & 2 & 8.7 & & - & - & \\
\hline & $91-100$ kg & 0 & - & & - & - & \\
\hline & $101-110 \mathrm{~kg}$ & 1 & 4.3 & & - & - & \\
\hline \multirow[t]{2}{*}{ Imatinib duration } & $1-5$ years & 14 & 60.9 & $4.3 \pm 2.08$ years & 11 & 100 & $2.2 \pm 0.4$ years \\
\hline & $6-10$ years & 9 & 39.1 & & - & - & \\
\hline \multirow[t]{2}{*}{ (+) Allopurinol } & Yes & 16 & 69.6 & - & 5 & 45.5 & - \\
\hline & No & 7 & 30.4 & - & 6 & 54.5 & - \\
\hline
\end{tabular}

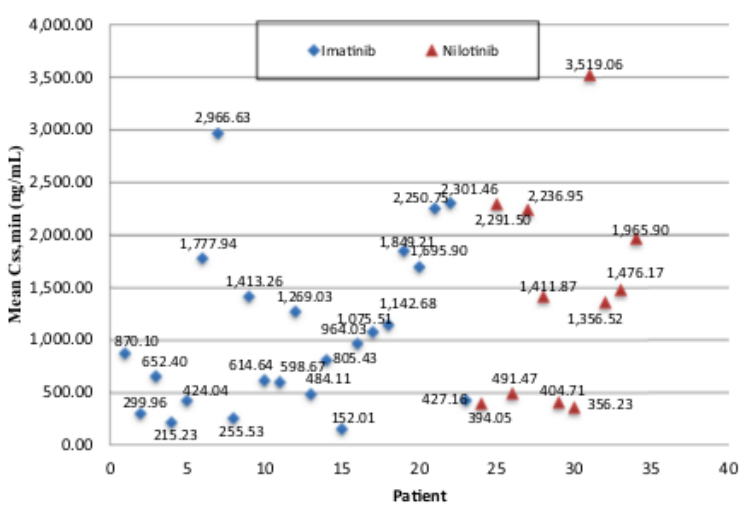

Figure 1: Distribution of imatinib and nilotinib $C_{\min }^{\infty}$.

Table 2: Imatinib and nilotinib average $C_{\min }^{\infty}$.

\begin{tabular}{lrrr}
\hline & Patient (n) & Average $C_{\min }^{\infty}(\mathrm{ng} / \mathrm{mL})$ & CV (\%) \\
\hline Imatinib & 23 & $1,065.46 \pm 765.71$ & 71.87 \\
Nilotinib & 11 & $1445 \pm 1,010.35$ & 69.88 \\
\hline
\end{tabular}

achieving a decrease in BCR-ABL transcripts compared to the group of patients who had $C_{\min 13}^{\infty}$ imatinib $<1,000 \mathrm{ng} / \mathrm{mL}$ (Figure 3). In contrast, there is no correlation between $C_{\min }^{\infty}$ and BCR-ABL ratio in the nilotinib group.

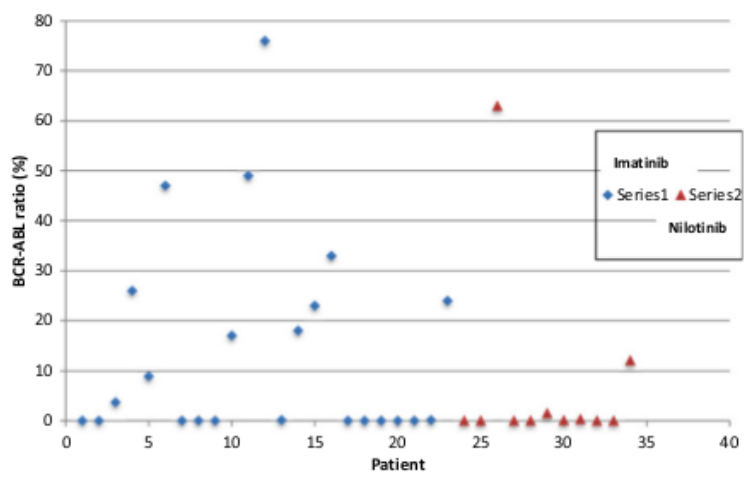

Figure 2: $B C R-A B L$ ratio distribution from imatinib and nilotinib group.

\section{Discussion}

CML is one of the myeloproliferative disorders in hematopoietic stem cells characterized by leukocytosis (WBC level $>100 \times 10^{\%} / \mathrm{L}$ ) and splenomegaly 19 bout $90 \%$ of CML patients have genetic abnormalities characterized by the presence of the Philadelphia chromosome $(\mathrm{Ph})$ with the fusion BCR-ABL gene. This fusion gene increases tyrosine kinase activity, which contributes to cell transformation 
12

Table 3: Patient's clinical response with BCR-ABL $\leq 0.1 \%$ and BCR-ABL $>0.1 \%$.

\begin{tabular}{|c|c|c|}
\hline & $\begin{array}{r}\text { BCR-ABL ratio } \\
\leq 0.1 \% \text { (MMR) }\end{array}$ & $\begin{array}{r}\text { BCR-ABL ratio } \\
>0.1 \% \text { (non-MMR) }\end{array}$ \\
\hline \multicolumn{3}{|l|}{ Imatinib } \\
\hline $\begin{array}{l}\text { Average Imatinib } \\
C_{\min }^{\infty}(\mathrm{ng} / \mathrm{mL})\end{array}$ & $1,381.95$ & 822.01 \\
\hline $\begin{array}{l}\text { Number of patients with } \\
C_{\min }^{\infty} \geq 1,000 \mathrm{ng} / \mathrm{mL}\end{array}$ & $7(30.43 \%)$ & $3(13.04 \%)$ \\
\hline $\begin{array}{l}\text { Number of patients with } \\
C_{\min }^{\infty}<1,000 \mathrm{ng} / \mathrm{mL}\end{array}$ & $3(13.04 \%)$ & $10(43.48 \%)$ \\
\hline \multicolumn{3}{|l|}{ Nilotinib } \\
\hline $\begin{array}{l}\text { Average Nilotinib } \\
C_{\min }^{\infty}(\mathrm{ng} / \mathrm{mL})\end{array}$ & $1,360.47$ & $1,595.29$ \\
\hline $\begin{array}{l}\text { Number of patients with } \\
C_{\min }^{\infty} \geq 800 \mathrm{ng} / \mathrm{mL}\end{array}$ & $5(45.45 \%)$ & $2(18.18 \%)$ \\
\hline $\begin{array}{l}\text { Number of patients with } \\
C_{\min }^{\infty}<800 \mathrm{ng} / \mathrm{mL}\end{array}$ & $2(18.18 \%)$ & $2(18.18 \%)$ \\
\hline
\end{tabular}

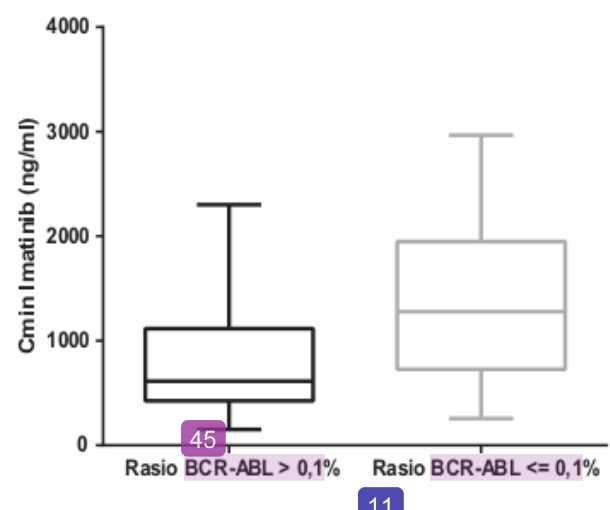

Figure 3: Imatinib $C_{\min }^{\infty}$ between patients with BCR-ABL ratio $>0.1 \%$ and patients with BCR-ABL $\leq 0.1 \%$.

and causes uncontrolled leukemic cell growth in hematopoietic cells [14].

Imatinib and nilotinib are oral targeted-therapy of TKI groups that selectively occupy the ATP domain in ABL, which inhibits the activity of Bcr-Abl tyrosine kinase protein. Inhibition to substrate phosphorylation will inhibit the signaling pathway, which causes leukemogenesis [15]. 44 Imatinib mesylate dosage of $400 \mathrm{mg} /$ day is a standard therapy in the management of chrof 14 phase of CML. Nilotinib has also been approved as a first-line therapy in chronic phase CML patients, clinically used in CML patients vipo resistant or tolerant to imatinib. By administering imatinib therapy at a dose of $400 \mathrm{mg} /$ day, CML patients can reach $C_{\min }^{\infty}$ target $(1,000 \mathrm{ng} / \mathrm{mL})$, a $C_{\text {min }}^{\infty}$ which can inhibit tyrosine kinase activity and therefore induce therapeutic responses. The parameter of molecular response was the ratio of BCR-ABL $[16,17]$. Meanwhile, the recommended target of nilotinib $C_{\min }^{\infty}$ for TDM practice, in general, is $\geq 800 \mathrm{ng} / \mathrm{mL}[18,19]$.

The results of this study showed that there was high interindividual variability both in imatinib $C_{\min }^{\infty}$ and nilotinib $C_{\text {min }}^{\infty}$. This high ${ }_{17}$ ariability was also reported in various previous studies. Data from the phase III IRIS study by Larson et al. showed a wide interindividual 54 iability of imatinib $C_{\min }^{\infty}$ that measured in ste $43 \mathrm{y}$-state, $1 \mathrm{~h}$ before the morning dose on 29th day in 351 patients who received a dose of imatinib $400 \mathrm{mg} /$ day. In another study, wide interindividual variability of imatinib $C_{\min }^{\infty}$ also obtained with the coefficient of variation of $40-60 \%[10,20,21]$.

5 Some of the factors that cause this interindividual variability include body size, age, sex, liver and renal function, interaction with other drugs which are taken together, adherence, and enzyme or transporter polymorphisms associated with PK/PD drugs [22]. In this study, there was no therapy other than imatinib/or nilotinib with/ without allopurinol, which was administered together by the patient, and there were no drug interactions between them. Compliance has been monitored by interviewing before sampling to ensure there is no missing dose at least 28 days before the day of sampling.

It has been reported in various studies that imatinib has a proportional dose-response relationship. The results of correlation analysis between $C_{\min }^{\infty}$ and molecular response (BCR-ABL ratio) showed that there was a correlatio53 the imatinib group [20].

The mean of imatinib $C_{\min }^{\infty}$ in patiegts who achieved the $\mathrm{BCR}-\mathrm{ABL}$ ratio ta 41 has been found higher than the mean of imatinib $C_{\min }^{\infty}$ in patients that did not reach the target 8CR-ABL ratio $(1,065.46 \mathrm{ng} / \mathrm{mL}$ vs. $822.01 \mathrm{ng} / \mathrm{mL})$. The $C_{\min }^{\infty} \geq 1,000 \mathrm{ng} / \mathrm{mL}_{23}$ s associated with an increased chance of achieving a BCR-ABL ratio of $\leq 0.1 \%$ (major molecular response or MMR). These results support the results of previous studies, which reported that an increase in imatinib $C_{\min }^{\infty}$ correlated ${ }_{11}$ th a decrease in BCR-ABL transcripts characterized by a BCR-ABL ratio of $\leq 0.1 \%[20,22]$. BCR-ABL ratio $\leq 0.1 \%$ (MMR) can indicate a decrease in the progression toward an acceleration orblastic phase. Unlike imatinib, in the nilotinib group, there is no correlation between $C_{\min }^{\infty}$ and BCR-ABL ratio even though higher $C_{\min }^{\infty}$ tends to have a higher MMR level. The absence of a correlation between nilotinib exposure and the response was thought to be due to the wide interindividual variability of

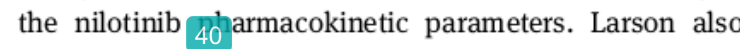
revealed that the relati ${ }_{21}$ hip between nilotinib exposure and clinical response was not as clear as that observed in patients with imatinib. This condition may be due to nilotinib being more potent than imatinib [11]. In a 
15

retrospective analysis of the Evaluating Nilotinib Efficacy and Safety in clinical Trials-newly diagnosed (ENESTnd) $2_{2} \mathrm{dy}$, it was found that there was a faster decrease of BCR-ABL ratio in the nilotinib group. The 6th month of the median BCR-ABL ratio in the nilotinib group was found to be similar to the 18th month of BCR-ABL ratio in the imatinib group. There vare reported to be more patients with nilotinib doses of 300 and $400 \mathrm{mg}$, which achieved a BCR-ABL ratio of $<10 \%$ in the 3rd month 38 mpared to imatinib (74, 78, and 61\%) [23]. The results of the Exploring Nilotinib BCR-ABL Effects (ENABL) study in the US on patients with sspoptimal response to imatinib therapy showed that a decrease in the BCR-ABL ratio occurred fastest in the first 3-9 months after nilotinib use. After that, it was tended to be a plateau [24]. In the present study, the BCR-ABL ratio was observed after the use of nilotinib for more than 12 months, while the majority of patients had used nilotinit 1 for more than 24 months and 7 (63.63\%) patients had achieved a BCR-ABL ratio of $\leq 0.1 \%$. Allegedly in the period of the implementation of the study, the BCR-A 37 ratio has entered the plateau period so that it may cause no correlation between $\mathrm{C}_{2}^{\infty}$ in and the BCR-ABL ratio.

The distribution profile of the $\mathrm{BCR}-\mathrm{ABL} / \mathrm{ABL}$ ratio achieved by patients in the nilotinib group (Figure 2) showed that some patients experience ${ }_{5}$ suboptimal responses. According to the guidelines of the European LeukemiaNet (ELN), all responses under the conditions of a major molecular response (BCR-ABL $\leq 0.1 \%$ IS) at the 18th month after the start of TKI therapy are considered sub9)timal [25]. Reflecting on previous studies, nilotinib $52 \mathrm{n} \geq 800 \mathrm{ng} / \mathrm{mL}$ was associated with the achievement of the BCR-ABL ratio $\leq 0.1 \%$ IS in the 12 th month, which indicates that nilotinib can inhibit tyrosine kinase activity well $[19,26]$. This may explain tat patients with nilotinib $C_{\min }^{\infty} \geq 800 \mathrm{ng} / \mathrm{mL}$ can achieve a BCR-ABL ratio of $\leq 0.1 \%$. The phenomenon of having a patient with high nilotinib $C_{\min }^{\infty}$, but still unable to achieve the BCR-ABL ratio $\leq 0.1 \%$ was thought to be due to TKI resistance.

Le 28 emia cell resistance to TKI can occur due to genetic mutations in the ABL tyrosine kinase domain and changes in expression of influx ${ }_{56}$ flux transporters [27]. Patients can experience multiple mutations in the BCR-ABL gene at the same time and result in heavier resistance. More than 90 different mut 36 ns have been found in different kinase domains [28]. In-vitro studies result showed that nilotinib has ${ }_{35}$ tivity against almost all cell cultures that are resistant to imatinib due to BCR-ABL mutations, except for T3151 mutants [29]. In contrast to imatinib, which requires the human organic cation transporter-1 (h-OCT1) to be uptaken into leukemia cells, nilotinib activity was found to be independent from h-OCT1 [30]. In contrast, various studies have shown the role of ATP Binding Cassette Subfamily B member 1 (ABCB1) and ATP Binding Cassette Subfamily $G$ member 2 (ABCG2) in the efflux mechanism of nilotinib from leukemia cells. In one study, it was found that the inhibition capacity of nilotinib tyrosine kinase decreased with the increasing levels of ABCB1. Therefore, $\mathrm{ABCB} 1$ overexpression can play a role in causing resistance to niloti ib [31-33]. Further research is needed to see mutations in the BCR-ABL gene and the expression of ABCB1 transporters in this group of patients to determine the possibility of nilotinib resistance.

\section{Conclusion}

There were high 27 terindividual variations of imatinib and nilotinib $C_{\min }^{\infty}$ in CML patients. Imatinib $C_{\min }^{\infty}$ correlated with $\mathrm{BCR}-\mathrm{ABL}$ ratios, but no correlation in nilotinib.

Acknowledgment: We would like to thank Dr. Soetomo General Hospital for granting permission to use the data provided in this study and the Tahir Foundation.

Research funding: This study was funded by the Minister of Research Technology and Higher Education of Indonesia and the Tahir Foundation.

Author contributions: All authors have accepted responsibility for the entire content of this manuscript and approved its submission.

Conflict of interest: The authors state that they have no conflict of interest.

Informed consent: Informed consent was obtained from all individuals included in this study.

\section{References}

1. Iqbal N, Iqbal N. Imatinib: a breakthrough of targeted therapy in cancer. Chemother Res Pract 2014:1-9. https://doi.org/10.1155/ 2014/357027.

2. Hamad A, Sahli Z, Sabban ME, Mouterik M, Nasr R. Emerging therapeutic strategies for targeting chronic myeloid leukemia stem cells. Stem Cells Inter 2013;2013:1-12.

3. Quintas-Cardama A, Cortes J, Kantarjian H, O'Brien S. Chronic myelogenous leukemia. In: Provan D, Gribben J, editors. Molecular hematology. UK: Wiley-Blackwell; 2010:76-87.

4. Savage DG, Antman KH. Imatinib mesylate-A new oral targeted therapy. N Engl J Med 2002;346:683-93.

5. Biswal $\mathrm{S}$. Novel agents in CML therapy: tyrosine kinase inhibitors and beyond. WebMedCentral 2012;3:1-12.

6. Kantarjian HM, Talpaz M, Giles F, O'Brien S, Cortes J. New insights into the pathophysiology of chronic myeloid leukemia and imatinib resistance. Ann Intern Med 2006;145:913-23.

7. Deiniger MW. Nilotinib CCR drug updates. Clin Cancer Res 2008; 14:4027-31.

8. Hardling M, Wei Y, Palmqvist L, Swolin B, Stockelberg D, Gustavsson B, et al. Serial monitoring of BCR-ABL transcripts in 
chronic myelogenous leukemia (CML) treated with imatinib mesylate. Med Oncol 2004;21:349-58.

9. Bintoro SU. Sejarah CML, Karakteristik Klinik CML, Resistensi terhadap imatinib. Dalam: Su B, editor. Chronic myelogenous leukemia: patogenesis, diagnosis dan terapi. Surabaya: Global Persada Press; 2014:1-26.

10. Larson RA, Druker BJ, Guilhot F, O’Brien SG, Riviere GJ, Krahnke T, et al. Imatinib pharmacokinetics and its correlation with response and safety in chronic-phase chronic myeloid leukemia: a subanalysis of the IRIS study. Am Soc Hematol 2008;111:4022-8.

11. Larson RA, Yin OQP, Hochhaus A, Saglio G, Clark RE, Nakamae H, et al. Population pharmacokinetic and exposure-response analysis of nilotinib in patients with newly diagnosed $\mathrm{Ph}+$ chronic myeloid leukemia in chronic phase. Eur J Clin Pharmacol 2012;68:723-33.

12. Takahashi N, Miura M, Scott SA, Kagaya H, Kameoka Y, Tagawa H, et al. Influence of CYP3A5 and drug transporters polymorphisms on imatinib trough concentration and clinical response among patients with chronic phase chronic myeloid leukemia. J Hum Genet 2010;55:731-7.

13. Pirro E, Francia SD, Martino FD, Fava C, Ulisciani S, Cambrin GR, et al. A new HPLC-UV validated method for therapeutic drug monitoring of tyrosine kinase inhibitors in leukemic patients. J Chromatogr Sci 2011;49:753-7.

14. Goldman JM, Melo JV. Chronic myeloid leukemia - advances in biology and new approaches to treatment. NEJM 2003;349:1451-61.

15. Patel D, Suthar MP, Patel V, Singh R. BCR ABL kinase inhibitors for cancer therapy. Int J Pharm Sci Drug Res 2010;2:80-90.

16. Ishikawa Y, Kiyoi H, Watanabe K, Miyamura K, Nakano Y, Kitamura $K$, et al. Trough plasma concentration of imatinib reflects BCR-ABL kinase inhibitory activity and clinical response in chronic-phase chronic myeloid leukemia: a report from the BINGO study. Cancer Sci 2010;101:2186-92.

17. Pavon V, Gomez R, Jaime JC, Hernandez P, Arencibia A, EspinosaMartinez $\mathrm{E}$. Introduction of imatinib as first-line therapy for chronic myeloid leukemia in Cuba. MEDICC Rev 2011;13:35-9.

18. Gao B, Yeap S, Clements A, Balakrishnar B, Wong M, Gurney H. Evidence for therapeutic drug monitoring of targeted anticancer therapies. J Clin Oncol 2012;30:4017-22.

19. Miura M. Therapeutic drug monitoring of imatinib, nilotinib and dasatinib for patients with chronic myeloid leukemia. Biol Pharm Bull 2015;38:645-54.

20. Picard S, Titier K, Etienne G, Teilhet E, Ducint D, Bernard M, et al. Trough imatinib plasma levels are associated with both cytogenetic and molecular responses to standard-dose imatinib in chronic myeloid leukemia. Blood 2007;109:3496-8.

21. Peng B, Hayes M, Resta D, Racine-Poon A, Druker BJ, Talpaz M, et al. Pharmacokinetics and pharmacodynamics of imatinib in a phase I trial with chronic myeloid leukemia patients. J Clin Oncol 2004;22:935-42.

22. Takahashi N, Wakita H, Miura M, Scott SA, Nishii K, Masuko M, et al. Correlation between imatinib pharmacokinetics and clinical response in Japanese patients with chronic - phase chronic myeloid leukemia. Clin Pharmacol Ther 2010;88: 809-13.

23. Savona MR, Saglio G. Identifying the time to change BCR-ABL inhibitor therapy in patients with chronic myeloid leukemia. Acta Haematol 2013;130:268-78.

24. Ailawadhy S, Akard LP, Miller CB, Jillella A, DeAngelo DJ, Ericson SG. Exploratory study on the impact of switching to nilotinib in 18 patients with chronic myeloid leukemia in chronic phase with suboptimal response to imatinib. Ther Adv Hematol 2017;8:3-12.

25. Baccarani M, Deininger MW, Rosti G, Hochhaus A, Soverini S, Apperley JF. European leukemia net recommendations for the management of chronic myeloid leukemia. Blood 2013;122: 872-80.

26. Takahashi N, Miura M, Kuroki J, Mitani K, Kitabayashi A, Sasaki O, et al. Multicenter phase II clinical trial of nilotinib for patients with imatinib-resistant or -intolerant chronic myeloid leukemia from the east Japan CML Study Group evaluation of molecular response and the efficacy and safety of nilotinib. Biomark Res 2014;2:1-9.

27. Galinsky I, Buchanan S. Guide to interpreting disease responses in chronic myeloid leukemia. J Adv Pract Oncol 2012;3:225-36.

28. Jabbour E, Parikh SA, Kantarjian H, Cortes J. Chronic myeloid leukemia - mechanism of resistance and treatment. Hematol Oncol Clin North Am 2015;25:981.

29. Jabbour E, Cortes J, Kantarjian H. Nilotinib for the treatment of chronic myeloid leukemia: an evidence-based review. Core Evid 2009;4:207-13.

30. van Erp NP, Gelderblom H, Guchelaar HJ. Clinical pharmacokinetcs of tyrosine kinase inhibitors. Cancer Treat Rev 2009;35:692-706.

31. Dohse M, Scharenberg C, Shukla S, Robey RW, Volkmann T, Deeken JF, et al. Comparison of ATP-binding cassette transporter interactions with the tyrosine kinase inhibitors imatinib, nilotinib and dasatinib. Drug Metab Dispos 2010;38:1371-80.

32. Eadie LN, Saunders VA, Hughes TP, White DL. Degree of kinase inhibition achieved in vitro by imatinib and nilotinib is decreased by high levels of ABCB1 but not ABCG2. Leuk Lymphoma 2013;54: 569-78.

33. Eadie LN, Hughes TP, White DL. Interaction of the efflux transporter $A B C B 1$ and $A B C G 2$ with imatinib, nilotinib and dasatinib. Clin Pharmacol Ther 2014;95:294-306. 
Relationship between trough level of tyrosine kinase inhibitor (imatinib and nilotinib) and BCR-ABL ratios in an Indonesian chronic-phase chronic myeloid leukemia $(\mathrm{CML})$ population

ORIGINALITY REPORT

$20 \%$

SIMILARITY INDEX
$9 \%$

INTERNET SOURCES
$19 \%$

PUBLICATIONS
$0 \%$

STUDENT PAPERS

\section{PRIMARY SOURCES}

1 Lorenzo Falchi, Viviana Appolloni, Lucia

Ferranti, Anna Marina. "Chapter 2 The Value of

Molecular Response in Chronic Myeloid

Leukemia: The Present and the Future",

IntechOpen, 2012

Publication

2 MT Corsetti, E Lerma, A Dejana, P Basta et al.

"Quantitative competitive reverse transcriptasepolymerase chain reaction for BCR-ABL on

Philadelphia-negative leukaphereses allows the

selection of low-contaminated peripheral blood

progenitor cells for autografting in chronic

myelogenous leukemia", Leukemia, 1999

Publication

Antonina Germano, Ida Rapa, Marco Volante,

Silvia De Francia et al. "RRM1 modulates

mitotane activity in adrenal cancer cells

interfering with its metabolization", Molecular

and Cellular Endocrinology, 2015 
4 R. Bitzur, H. Cohen, Y. Kamari, D. Harats.

"Intolerance to Statins: Mechanisms and

Management", Diabetes Care, 2013

Publication

5 epdf.tips

6 www.ncbi.nlm.nih.gov Internet Source

7 repub.eur.nl

Internet Source

8 V. Gotta, N. Widmer, L. A. Decosterd, Y.

Chalandon et al. "Clinical usefulness of

therapeutic concentration monitoring for imatinib

dosage individualization: results from a

randomized controlled trial", Cancer

Chemotherapy and Pharmacology, 2014

Publication

$9 \quad$ www.haematologica.org

Internet Source

$1 \%$

10 Kim, T D, D Rea, M Schwarz, P Grille, F E

Nicolini, G Rosti, L Levato, F J Giles, H

Dombret, T Mirault, H Labussière, R Lindhorst, W Haverkamp, I Buschmann, B Dörken, and P

$\mathrm{D}$ le Coutre. "Peripheral artery occlusive disease in chronic phase chronic myeloid leukemia 
patients treated with nilotinib or imatinib",

Leukemia, 2013.

Publication

11

Timothy P. Hughes, Andreas Hochhaus, Susan

Branford, Martin C. Müller et al. "Long-term

prognostic significance of early molecular

response to imatinib in newly diagnosed chronic

myeloid leukemia: an analysis from the

International Randomized Study of Interferon

and STI571 (IRIS)", Blood, 2010

\section{Publication}

12 clincancerres.aacrjournals.org

Internet Source

13 Kazunori Ohnishi. "Long-term outcome following imatinib therapy for chronic myelogenous leukemia, with assessment of dosage and blood levels: the JALSG CML202 study", Cancer Science, 04/2012 Publication

Francis J Giles, Gianantonio Rosti, Photis Beris,

Richard E Clark et al. "Nilotinib is superior to imatinib as first-line therapy of chronic myeloid leukemia: the ENESTnd study", Expert Review of Hematology, 2014 
16 Cancer Drug Discovery and Development, 2014.

17 www.nature.com Internet Source

18 www.researchgate.net Internet Source

19 www.frontiersin.org Internet Source

20 Tang, Xing, XiaoLin Tian, and Lei Ci.

"Preparation and Evaluation of $\mathrm{pH}$-Dependent

Gradient-Release Pellets for TCM", Drug

Development and Industrial Pharmacy, 2004.

Publication

21 Richard A. Larson, Ophelia Q. P. Yin, Andreas Hochhaus, Giuseppe Saglio et al. "Population

pharmacokinetic and exposure-response analysis of nilotinib in patients with newly diagnosed $\mathrm{Ph}+$ chronic myeloid leukemia in chronic phase", European Journal of Clinical Pharmacology, 2011

Publication

22 worldwidescience.org

"Abstracts", British Journal of Haematology, 2014. 
24 journals.lww.com

Internet Source

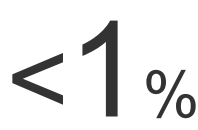

25 Kim, Dennis Dong Hwan, Nada Hamad, Hong

Gi Lee, Suzanne Kamel-Reid, and Jeffrey $\mathrm{H}$.

Lipton. "BCR/ABL level at 6 months identifies

good risk CML subgroup after failing early

molecular response at 3 months following

imatinib therapy for $\mathrm{CML}$ in chronic phase :

BCR/ABL PCR at 3 and 6 Months after

Imatinib", American Journal of Hematology,

2014.

Publication

26

Zhongzheng Lu. "Pristimerin induces apoptosis

in imatinib-resistant chronic myelogenous

leukemia cells harboring T315I mutation by

blocking NF-KB signaling and depleting Bcr-

Abl", Molecular Cancer, 2010

Publication

Bouchet, StÃ@phane, Karine Titier, Nicholas Moore, RÃ@gis Lassalle, Basmah Ambrosino, Sylvie Poulette, Peter Schuld, Coralie Belanger, FranÃßois-Xavier Mahon, and Mathieu Molimard. "Therapeutic drug monitoring of imatinib in chronic myeloid leukemia: experience from 1216 patients at a centralized laboratory", Fundamental and Clinical Pharmacology, 2012. 
28 D. M. Ross. "Current and emerging tests for the laboratory monitoring of chronic myeloid leukaemia and related disorders", Pathology,

$3 / 2008$

Publication

Breccia, Massimo, Fabio Stagno, Luigiana

Luciano, Elisabetta Abruzzese, Mario

Annunziata, Mariella D'Adda, Alessandro Maggi,

Nicola Sgherza, Antonella Russo-Rossi, Patrizia

Pregno, Fausto Castagnetti, Alessandra lurlo,

Roberto Latagliata, Michele Cedrone, Nicola Di

Renzo, Federica Sorà, Giovanna Rege-

Cambrin, Giorgio La Nasa, Anna Rita

Scortechini, Giovanna Greco, Luca

Franceschini, Simona Sica, Monica Bocchia,

Monica Crugnola, Esther Orlandi, Attilio Guarini,

Giorgina Specchia, Gianantonio Rosti,

Giuseppe Saglio, and Giuliana Alimena.

"Dasatinib first-line: Multicentric Italian

experience outside clinical trials", Leukemia

Research, 2016.

Publication

P La Rosée. "Imatinib therapy in chronic myelogenous leukemia: strategies to avoid and

overcome resistance", Leukemia, 08/2004

Publication

gupea.ub.gu.se 
Manuel García-Ferrer, Aneta Wojnicz, Gina Mejía, Dora Koller, Pablo Zubiaur, Francisco Abad-Santos. "Utility of Therapeutic Drug Monitoring of Imatinib, Nilotinib, and Dasatinib in

Chronic Myeloid Leukemia: A Systematic Review and Meta-analysis", Clinical Therapeutics, 2019

\section{Publication}

Giulia Marzocchi, Fausto Castagnetti, Simona Luatti, Carmen Baldazzi et al. "Variant Philadelphia translocations: molecularcytogenetic characterization and prognostic influence on frontline imatinib therapy, a GIMEMA Working Party on CML analysis", Blood, 2011

Publication

34 www.hematologyandoncology.net Internet Source

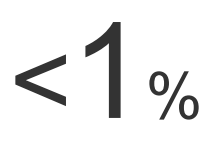

35 Timothy Hughes. "Monitoring Disease Response", Hematologic Malignancies, 2007

Lisa Kujawski, Moshe Talpaz. "Strategies for overcoming imatinib resistance in chronic myeloid leukemia", Leukemia \& Lymphoma, 2009 
37 Yanzhe Xia, Sile Chen, Meijuan Luo, Jingjing Wu, Shirong Cai, Yulong He, Xiao Chen, Xinhua

Zhang. "Correlations between imatinib plasma trough concentration and adverse reactions in

Chinese patients with gastrointestinal stromal tumors", Cancer, 2020

Publication

38 Sikander Ailawadhi, Luke P. Akard, Carole B. Miller, Anand Jillella et al. "Exploratory study on the impact of switching to nilotinib in 18 patients with chronic myeloid leukemia in chronic phase with suboptimal response to imatinib", Therapeutic Advances in Hematology, 2016 Publication

39 www.karger.com Internet Source

41 D Rea. "Imatinib dose escalation for chronic phase-chronic myelogenous leukaemia patients in primary suboptimal response to imatinib 400 mg daily standard therapy", Leukemia, 02/26/2009

Publication 
Ghavamzadeh, Kamran Alimoghaddam, Nahid Mobarghei Dinan, Mohammad-Reza Rouini.

"Population pharmacokinetics of imatinib in

Iranian patients with chronic-phase chronic

myeloid leukemia", Cancer Chemotherapy and

Pharmacology, 2014

Publication

43 Elias Jabbour, Jorge E. Cortes, Hagop M.

Kantarjian. "Molecular monitoring in chronic

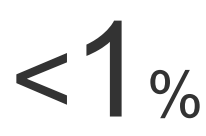

myeloid leukemia", Cancer, 2008

Publication

44 academic.oup.com

Internet Source

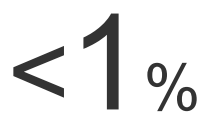

45 Jabbour, Elias, and Hagop Kantarjian. "Chronic myeloid leukemia: 2014 update on diagnosis,

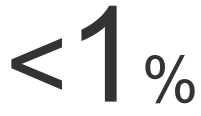
monitoring, and management", American

Journal of Hematology, 2014.

Publication

46 bpspubs.onlinelibrary.wiley.com

Internet Source

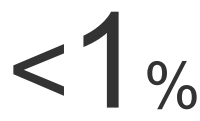

47 Rao, Kamakshi $\vee$, Andrea lannucci, and Elias

Jabbour. "Current and Future Clinical Strategies

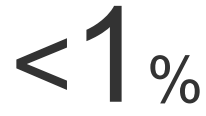
in the Management of Chronic Myeloid

Leukemia", Pharmacotherapy The Journal of

Human Pharmacology and Drug Therapy, 2010.

Publication

journals.plos.org 
49 Margaret von Mehren, Nicolas Widmer.

"Correlations between imatinib pharmacokinetics, pharmacodynamics, adherence, and clinical response in advanced metastatic gastrointestinal stromal tumor (GIST): An emerging role for drug blood level testing?", Cancer Treatment Reviews, 2011 Publication

50 Remy B. Verheijen, Huixin Yu, Jan H.M.

Schellens, Jos H. Beijnen, Neeltje Steeghs,

Alwin D.R. Huitema. "Practical

Recommendations for Therapeutic Drug

Monitoring of Kinase Inhibitors in Oncology",

Clinical Pharmacology \& Therapeutics, 2017

Publication

51

Islem Ben Hassine, Hanene Gharbi, Ismail

Soltani, Mouheb Teber et al. "hOCT1 gene expression predict for optimal response to Imatinib in Tunisian patients with chronic myeloid leukemia", Cancer Chemotherapy and Pharmacology, 2017

Publication

Hagop Kantarjian, Jorge Cortes.

"Considerations in the Management of Patients With Philadelphia Chromosome-Positive 
Chronic Myeloid Leukemia Receiving Tyrosine Kinase Inhibitor Therapy", Journal of Clinical

Oncology, 2011

Publication

53

Saleem, Mohamed, Goce Dimeski, Carl M.

Kirkpatrick, Paul J. Taylor, and Jennifer H.

Martin. "Target Concentration Intervention in

Oncology : Where Are We At?", Therapeutic

Drug Monitoring, 2012.

Publication

54

Filppula, A M, A Tornio, M Niemi, P J

Neuvonen, and J T Backman. "Gemfibrozil

Impairs Imatinib Absorption and Inhibits the

CYP2C8-Mediated Formation of Its Main

Metabolite", Clinical Pharmacology \&

Therapeutics, 2013.

Publication

55

Radhamani Kannaiyan, Daruka Mahadevan. "A

comprehensive review of protein kinase inhibitors for cancer therapy", Expert Review of Anticancer Therapy, 2018

Publication

Karmen Stankov. "Translational research in

complex etiopathogenesis and therapy of hematological malignancies: the specific role of tyrosine kinases signaling and inhibition", Medical Oncology, 12/03/2008 
Tortorella, Stephanie M, Andrew Hung, and

Tom Karagiannis. "The implication of cancer progenitor cells and the role of epigenetics in the development of novel therapeutic strategies for chronic myeloid leukemia", Antioxidants \& Redox Signaling, 2014.

Publication

58

Changhoon Yoo, Min-Hee Ryu, Baek-Yeol

Ryoo, Mo Youl Beck, Heung-Moon Chang, Jae-

Lyun Lee, Tae Won Kim, Yoon-Koo Kang.

"Changes in imatinib plasma trough level during long-term treatment of patients with advanced gastrointestinal stromal tumors: correlation between changes in covariates and imatinib exposure", Investigational New Drugs, 2011 Publication

59

Tim P. Hughes. "Frequency of Major Molecular Responses to Imatinib or Interferon Alfa plus Cytarabine in Newly Diagnosed Chronic Myeloid Leukemia", New England Journal of Medicine, $10 / 09 / 2003$

Publication

60

Elias J Jabbour, Jorge E Cortes, Hagop M Kantarjian. "Tyrosine kinase inhibition: a therapeutic target for the management of chronic-phase chronic myeloid leukemia", Expert Review of Anticancer Therapy, 2014 
Elizabeth Irvine, Casey Williams. "Treatment-, Patient-, and Disease-Related Factors and the Emergence of Adverse Events with Tyrosine Kinase Inhibitors for the Treatment of Chronic Myeloid Leukemia", Pharmacotherapy: The Journal of Human Pharmacology and Drug Therapy, 2013 
Relationship between trough level of tyrosine kinase inhibitor (imatinib and nilotinib) and BCR-ABL ratios in an Indonesian chronic-phase chronic myeloid leukemia (CML) population

GRADEMARK REPORT

FINAL GRADE

10

\section{PAGE 1}

PAGE 2

PAGE 3

PAGE 4

PAGE 5

PAGE 6
GENERAL COMMENTS

Instructor 